\title{
The Paradox of the Long-Term Positive Effects of a North American Crayfish on a European Community of Predators
}

\author{
ZULIMA TABLADO, ${ }^{*} \ddagger$ JOSÉ L. TELLA, ${ }^{*}$ JOSÉ A. SÁNCHEZ-ZAPATA, † AND FERNANDO HIRALDO* \\ *Department of Conservation Biology, Estación Biológica de Doñana (CSIC), Avda Américo Vespucio s/n, 41092 Sevilla, Spain \\ †Area de Ecología, Universidad Miguel Hernández, 03202 Elche, Alicante, Spain
}

\begin{abstract}
Invasions of non-native species are one of the major causes of losses of native species. In some cases, however, non-natives may also have positive effects on native species. We investigated the potential facilitative effects of the North American red swamp crayfish (Procambarus clarkii) on the community of predators in southwestern Spain. To do so, we examined the diets of predators in the area and their population trends since introduction of the crayfish. Most predator species consumed red swamp crayfish, which sometimes occurred in over 50\% of their diet samples. Moreover, the abundance of species preying on crayfish increased significantly in the area as opposed to the abundance of herbivores and to predator populations in other areas of Europe, where those predators are even considered threatened. Thus, we report the first case in which one non-native species is both beneficial because it provides prey for threatened species and detrimental because it can drive species at lower trophic levels to extinction. Increases in predator numbers that are associated with non-native species of prey, especially when some of these predators are also invasive non-natives, may increase levels of predation on other species and produce cascading effects that threaten native biota at longer temporal and larger spatial scales. Future management plans should include the complexity of interactions between invasive non-natives and the entire native community, the feasibility of successful removal of non-native species, and the potential social and economic interests in the area.
\end{abstract}

Keywords: diet shift, facilitative effects, invasive prey, non-native species, Procambarus clarkii, predator community, red swamp crayfish

La Paradoja de los Efectos Positivos a Largo Plazo de un Langostino Norteamericano sobre una Comunidad de Depredadores Europeos

Resumen: Las invasiones de especies exóticas son una de las principales causas de la pérdida de especies nativas. Sin embargo, en algunos casos las especies exóticas también pueden tener efectos positivos sobre las especies nativas. Investigamos los efectos facilitadores potenciales del cangrejo de río Procambarus clarkii sobre la comunidad de depredadores en el suroeste de España. Para ello, examinamos las dietas de los depredadores en el área y sus tendencias poblacionales desde la introducción del cangrejo. La mayoría de las especies de depredadores consumieron cangrejo, que en algunos casos apareció en más del 50\% de las muestras de su dieta. Más aún, la abundancia de las especies depredadoras de cangrejo aumentó significativamente en el área a diferencia de la abundancia de los herbívoros y de las poblaciones de depredadores en otras áreas de Europa, en las que los depredadores incluso están considerados como amenazados. Por lo tanto, presentamos el primer caso en el que una especie exótica es tanto beneficiosa porque proporciona presas para especies amenazadas como perjudicial porque puede hacer que especies en los niveles tróficos inferiores se extingan. Los incrementos en el número de depredadores asociados a especies de presas exóticas, especialmente cuando algunos de esos depredadores también son especies exóticas invasoras, pueden incrementar los niveles 

de depredación sobre otras especies y producir efectos en cascada que amenacen la biota nativa a escalas temporales más largas y espaciales más extensas. Los futuros planes de manejo deberían incluir la complejidad de interacciones entre exóticas invasoras y toda la comunidad nativa, la factibilidad de eliminación exitosa de especies exóticas y los potenciales intereses sociales y económicos en el área.

Palabras Clave: cambio de dieta, comunidad de depredadores, efectos facilitadores, especies exóticas, presa invasora, Procambarus clarkii

\section{Introduction}

Anthropogenic introduction of species is one of the main drivers of global environmental change and losses of native species (Sala et al. 2000). Most research has focused only on the negative impacts of non-native species on native biota, including competition, predation, hybridization, disease transmission, and changes in ecosystem functioning (Wittenberg \& Cock 2001; Crooks 2002). As a result, eradication programs have been suggested or even carried out in many cases (Myers et al. 1998, 2000).

Results of recent studies show that sometimes nonnative species have positive effects on native biota (Rodríguez 2006), which complicates management of the non-native species (Van Riel et al. 2000). Nevertheless, the few examples available thus far deal with only one or a few native species that benefit from the presence of invaders (Schiffman 1994; Barber et al. 2008). We investigated a situation in which a non-native species positively influences numerous species in the invaded community, some of which are threatened (BirdLife International 2004).

The red swamp crayfish (Procambarus clarkii) is native to the southeastern United States and northern Mexico. Currently it is the most widespread crayfish in the world and is present on all continents except Australia and Antarctica (Lodge et al. 2000; Gherardi 2006). The species colonized our study area in southwestern Spain in 1973 when juvenile crayfish escaped from an aquaculture pond in Puebla del Río (Seville), which was its first known location in Europe (Geiger et al. 2005).

Like other crayfish species, the red swamp crayfish interacts with species in several trophic levels in the systems it colonizes (Geiger et al. 2005; Gherardi 2006). Red swamp crayfish have concerned scientists and managers (Gherardi \& Holdich 1999; Rodriguez et al. 2005) because this species acts as a strong ecosystem engineer. It efficiently grazes on macrophytes, often shifting marshlands from macrophyte-dominated, clear-water systems to phytoplankton-driven, turbid systems (Rodriguez et al. 2003; Geiger et al. 2005).

Moreover, red swamp crayfish exemplifies the debate on the extent to which non-native species are causing the extinction of native species (Gurevitch \& Padilla 2004; Clavero \& García-Berthou 2005) because it has led to large-scale extirpations of the native crayfish by transmit- ting a fungal plague, Aphanomyces astaci. This fungus is endemic to many North American crayfish, but is lethal to the European species (Gherardi \& Holdich 1999; Geiger et al. 2005; Gherardi 2007).

More recently, declines in abundance of native amphibians and invertebrates have also been linked to the expansion of this crayfish (Cruz et al. 2006; Gherardi \& Acquistapace 2007). Red swamp crayfish is 1 of the 10 invasive species of greatest ecosystem-level concern in Europe (Vilà et al. 2009). In contrast, some vertebrate species have incorporated this new food item into their diets (Geiger et al. 2005). Nevertheless, no quantitative studies have demonstrated positive effects on the population dynamics of native predators by this or any other invasive, generalist arthropod (Geiger et al. 2005; Snyder \& Evans 2006).

To our knowledge ours is the first study to show the positive effects of an otherwise detrimental invader on a community of predator species. This finding is especially important in the Guadalquivir marshes, which is a Biosphere Reserve and one of the main European areas for the conservation of breeding and wintering populations of species threatened on a continental scale.

\section{Methods}

\section{Study Area}

The study was conducted in the Guadalquivir marshes in southwestern Spain $\left(37^{\circ} \mathrm{N}, 6^{\circ} 30^{t} \mathrm{~W}\right)$, an area of approximately $2300 \mathrm{~km}^{2}$. Most of the area has been designated natural or national park by the Spanish government and was designated a UNESCO Biosphere Reserve in 1981. Temperatures in the area range from an average of $10{ }^{\circ} \mathrm{C}$ in January to $24{ }^{\circ} \mathrm{C}$ in August. Most precipitation falls between October and April, but the amount and timing of precipitation changes substantially among years. Main vegetation types are Mediterranean scrubland, coastal sand dunes, and marshes. This marshland remains flooded from October to June and in recent decades, about one-third of its total area has been transformed to rice fields and fish farms.

\section{Dietary Analyses}

To study the effects of the invasive red swamp crayfish on the vertebrate community, we first investigated to what 
extent predator species are feeding on this novel food resource. We examined the food habits of 41 predators after the invasion of red swamp crayfish (Supporting Information). For 24 species of birds, we collected and analyzed the content of pellets in different seasons (breeding and nonbreeding), types of marshes (natural versus rice fields), and years (2001 and 2002).

When bird pellets were not available, we used nest remains or nestling regurgitations during breeding, and direct observations of foraging animals for the rest of the year. For direct observations, we used telescopes set at a distance of $>50 \mathrm{~m}$ to avoid disturbance, and to avoid pseudoreplication we observed only three distant individual birds per species within each foraging flock. For other predator species present in the study area, we used published information on their diets. These "other" predator species included seven other species of birds, six species of mammals (carnivores), two species of reptiles, and two species of fish (Supporting Information).

We built a generalized linear mixed model (GLMM) to assess whether the occurrence of crayfish in the diet of predators was associated with year, season, or marshland type. We used data on waterfowl species that we found preying on crayfish in at least one of the seasons, marsh types, and years (Supporting Information). The dependent variable, binomially distributed and with a logit link function, was the presence or absence of crayfish remains in a given sample (individual pellet, regurgitated material, remains sampled per nest, or observation of predator feeding [ $n=1644])$. We added the species of predator, sampling session (i.e., the flock or breeding location from which several dietary samples were obtained), and the type of dietary sample as random factors to account for potential autocorrelation within species and sampling techniques.

We also assessed potential long-term temporal changes in the consumption of crayfish by a generalist predator, the Black Kite (Milvus migrans). This is a medium-sized raptor that preys opportunistically on freshwater and terrestrial small- to medium-sized invertebrates and vertebrates (Delibes 1975). From 1976 to 2002, we collected prey remains in an average of 79 nests per year (total 2131 nests) when nestlings were close to fledging. We assessed whether crayfish consumption was related to time since colonization with two generalized linear models (GLMs). These models regressed the annual percentage of pairs of Black Kites feeding on crayfish and percentage of crayfish in nest remains ( $n=27$ years in both cases) on time since colonization. Both models had a negative binomial distribution, due to overdispersion, and a log-link function against time since crayfish colonized the area (crayfish_year). In both models, we also included annual precipitation as an independent variable because precipitation affects both primary productivity (Finlayson et al. 2008) and the abundance of some birds (Rendón et al. 2008).
Changes in Abundance of Native Species

We obtained data on long-term abundances of 27 vertebrate species in the Guadalquivir marshes. These species included birds that prey and do not prey on red swamp crayfishes. We considered crayfish predators those species for which the red swamp crayfish was at least $10 \%$ of their diet. We obtained abundance data from the Natural Processes Monitoring Team of the Doñana Biological Station (http://www-rbd.ebd.csic.es/Seguimiento/ seguimiento.htm). These data were derived from aerial and ground surveys of individuals in the nonbreeding season and ground counts of breeding pairs during the reproductive period. Throughout the years, the same amount of effort was applied to the surveys, and most surveys were conducted by the same observers. Aerial censuses were conducted in a light aircraft flying $40 \mathrm{~m}$ over inundated marshland. Ground counts (on horseback or by foot) covered the entire study area.

For each season, we applied GLMMs to assess whether crayfish invasion was associated with changes in the abundances of vertebrate species feeding on them (Supporting Information). Annual counts of each predator species were the dependent variables $(n=620$, nonbreeding season; $n=468$, breeding season). We used a negative binomial distribution and a log-link function for both seasons. Because data on annual abundances of crayfish were not available, we examined the relationship between crayfish invasion and abundance by including the year since its colonization of the area (crayfish year) while controlling for annual precipitation. We included year and bird species as random terms in the models to control for potential within-year correlation among abundances of different bird species (due to unmeasured effects other than precipitation) and longitudinal correlation of abundances within each species respectively.

To avoid confounding presence of red swamp crayfish with other human-induced effects (Gurevitch \& Padilla 2004), such as the reduced mortality of native species due to the protection of the area since 1989, we introduced diet as a variable. Diet was the percentage of crayfish in dietary samples of each species (Supporting Information). When there was more than one value of percentage per species, we used the higher value. We compared changes in abundance of bird species occurring in the same marshland type but consuming different amounts of crayfish by adding the interaction between crayfish year and diet.

For the nonbreeding season, we included herbivorous species of waterfowl ( $0 \%$ of crayfish in diet; Supporting Information) in the same GLMM because these species were also counted during aerial surveys. Nevertheless, systematic counts for herbivorous species during the breeding season were not conducted, so we used data on abundance from our records for Purple Gallinule (Porphyrio porphyrio), from the Natural Processes 
Monitoring Team of the Doñana Biological Station for Crested Coot (Fulica cristata), and from the Red Book of Endangered Vertebrates of Andalusia for Marbled Teal (Marmaronetta angustirrostris) (Franco \& Rodriguez 2001).

Abundance trends of additional nonpredatory species were estimated through a questionnaire given to researchers, field technicians, and park rangers (total 27 people) who had worked in the study area for decades (e.g., Lozano-Montes et al. 2008). Without knowing our research aims, they were asked to classify long-term trends in abundance of different herbivore species as increasing or not increasing. We included three predator species whose long-term abundances were known to assess whether their estimated trends in abundance coincided with actual changes in abundance. We used a Fisher's test to compare known abundance trends of predators with those of nonpredatory bird species that also breed in the Guadalquivir marshes (Supporting Information; $n=25$ ).

It could be argued that local predator abundances are determined by larger-scale population trends rather than by crayfish colonization of the area. Thus, we performed paired Wilcoxon tests to compare local trends in abundance of predator species with trends in abundance of those predators throughout Europe. We selected predator species for which both kinds of information were available $(n=14)$. Long-term information at the European scale was only available for the breeding season (Birdlife International 2004). We obtained local trends in predator abundance from data on the annual number of breeding pairs, but, to facilitate statistical comparisons, we classified these abundances according to the classes used by Birdlife International (2004) for European trends (Supporting Information).

\section{Results}

Diet of Native Predators

Over $60 \%$ of the predators wintering or breeding or both in the Guadalquivir marshes incorporated crayfish as
$>10 \%$ of their prey, often exceeding $50 \%$ of the contents of food samples (Fig. 1; Supporting Information). Species preying on red swamp crayfish were mostly waterbirds (Ciconiiformes, Charadriiformes). The proportion of red swamp crayfish in the diet of these bird species differed among seasons $(F=8.22, p=0.0042$, df $=1496)$ and types of marshland $(F=43.89, p<0.0001, \mathrm{df}=1496)$ when predator species and sampling method were controlled for and fitted as random terms in the same GLMM.

The effect of year was not significant $(p=0.3864)$. The proportion of crayfish in the diet of birds was greater during the nonbreeding season than during the breeding season and in transformed rather than in natural marshes.

Among mammals, only the otter (Lutra lutra) ate crayfish. Crayfish constituted over $75 \%$ of otter diets even in the first 10 years after crayfish colonization (Supporting Information). Crayfish comprised $45-65 \%$ of the diets of the two species of turtles and fish during the birdbreeding season. No information was available to assess the relationships between year, season, or vegetation and the diets of these few species of mammals, turtles, and fish.

The long-term monitoring (1976-2002) of the diet of Black Kites breeding in the study area showed an increase over time of both the percentage of pairs preying on red swamp crayfish $(F=16.06, p=0.0005, \mathrm{df}=24)$ and the percentage of crayfish in kite diets $(F=9.78, p=0.0046$, $\mathrm{df}=24)$. There was a delay of 10 years between crayfish colonization and regular consumption of crayfish (i.e., crayfish were $>10 \%$ of diet) by Black Kites (Fig. 2).

Trends in Abundance of Predators

Abundances of birds exploiting red swamp crayfish increased in the nonbreeding $(F=6.83, p=0.0092$, $\mathrm{df}=560)$ and breeding seasons $(F=6.31, p=0.0126$, $\mathrm{df}=296$ ), after crayfish colonization, when we controlled for annual precipitation (which was only significant for the breeding season: $F=9.69, p=0.0020$, $\mathrm{df}=296$ ), year, and species as random factors in the same models. This increase in abundance was significantly

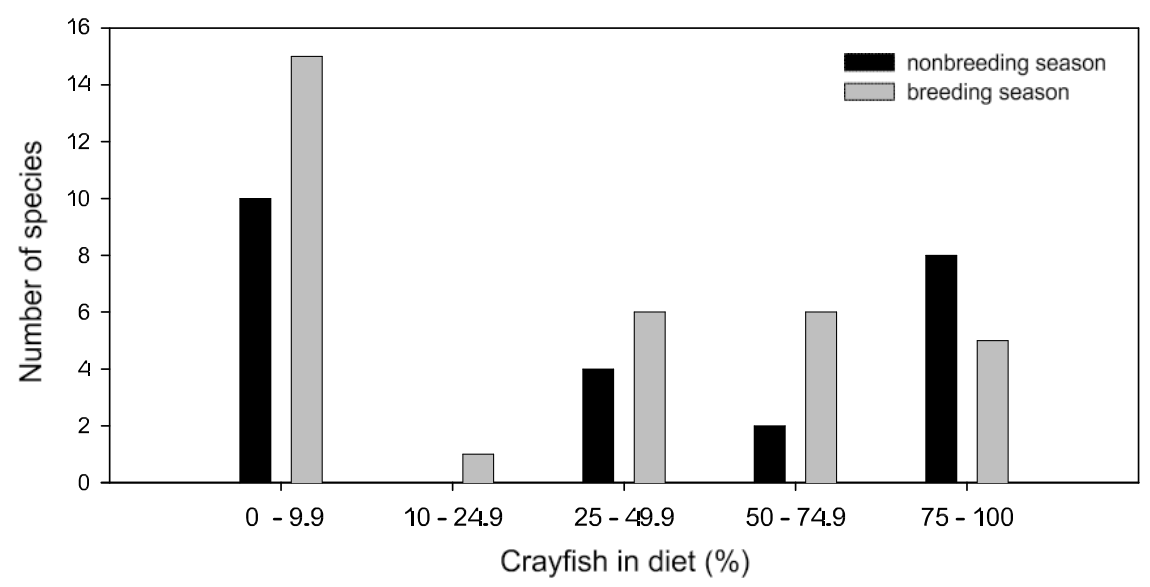

Figure 1. Percentage of red swamp crayfish in the diet of predators $(\mathrm{n}=41)$ in the Guadalquivir wetlands during the breeding and nonbreeding seasons. When more than one value for a species (e.g., different years) was available, the average value is shown. 


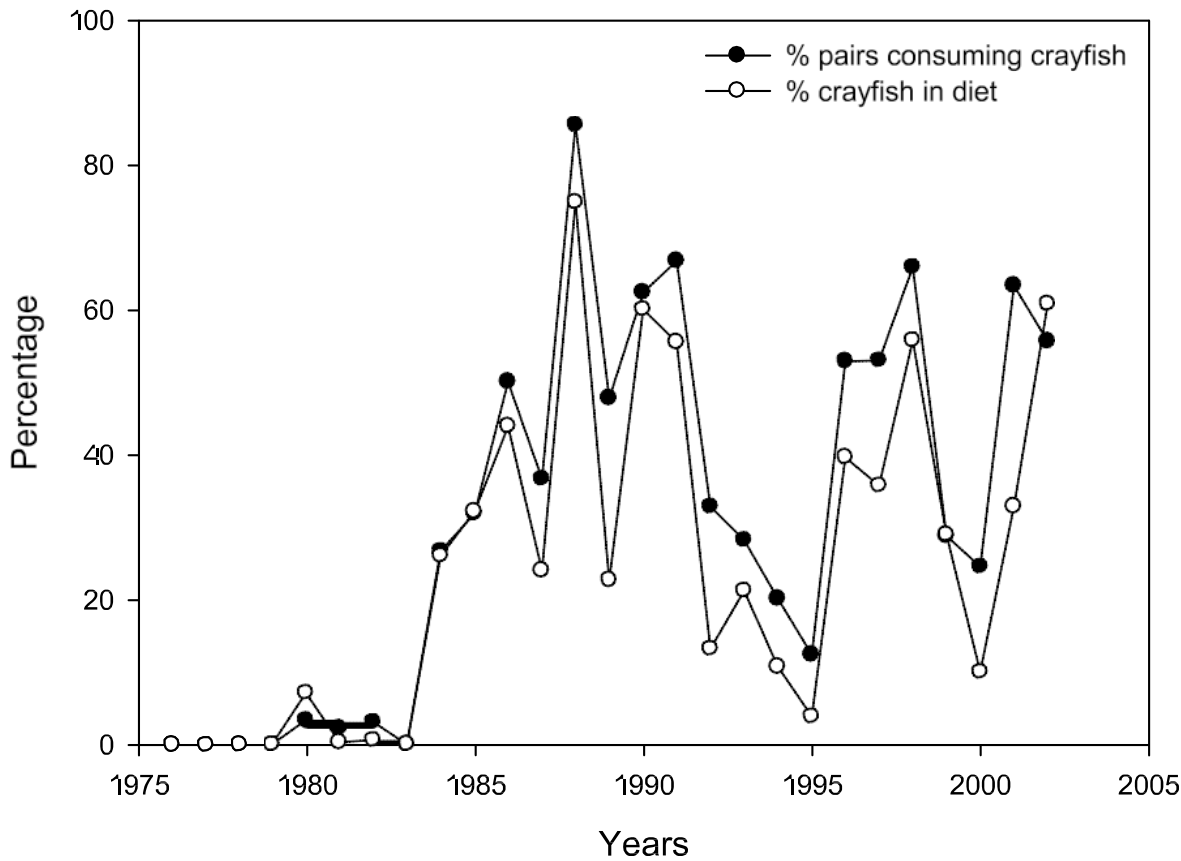

Figure 2. Changes in the consumption of crayfish by breeding pairs of Black Kites from 1976 to 2002. greater for predators that consumed more crayfish than for predators that consumed less crayfish or herbivores (crayfish year $\times$ diet in nonbreeding season, $F=136.12$, $p<0.0001$, df $=560$, and in the breeding season, $F=11.32, p=0.0009, \mathrm{df}=296)($ Fig. 3). After 1985 abundances of predators increased at a much higher rate (Figs. 3a-b).

Long-term abundance trends of crayfish predators during the breeding season differed significantly from those of herbivorous species that also reproduce in the Guadalquivir marshes. Whereas all 14 predatory species showed a positive trend, only 1 of 11 herbivores increased its breeding abundance (Fisher's test, $p<0.0001$; Supporting Information). Breeding abundances of these 14 species of crayfish predators increased significantly more in our study area than at the European scale ( $Z=-2.74, p=0.006$; Supporting Information).

\section{Discussion}

The non-native red swamp crayfish included more than $10 \%$ of the diet of more than half the predator species wintering or breeding in the Guadalquivir marshes. These results are consistent with previous evidence on crayfish consumption by a smaller number of predator species in different regions (Geiger et al. 2005; Poulin et al. 2007). In contrast to other parts of the world that have been colonized by red swamp crayfish, native crayfish were absent from our study area. Thus, the dietary shift can be interpreted as a functional response to the availability of novel prey. Generalist predators consume crayfish because it is now the largest-bodied $(>20 \mathrm{~g})$ invertebrate in this aquatic ecosystem. The results of the long-term mon- itoring of the diet of Black Kites suggested that crayfish were not widely available to generalist predators until 10 years after colonization and after that crayfish abundance varied widely.

Despite the high variability in proportion of crayfish consumed by different species of predators (Fig. 1), some clear patterns emerged. Contrary to the results of previous studies (Beja 1996; Correia 2001), crayfish consumption increased during the nonbreeding season. Autumn movements of crayfish toward or among newly flooded locations could make them more obvious to predators (Correia 2001) or more widely distributed and accessible. This result, however, might also be due to a lower availability of alternative prey in the area during autumn and winter. Variations in crayfish abundance relative to native prey may also be causing the differences in consumption rates between marshland types. The higher availability and intake of crayfish in transformed marshland (mostly occupied by rice fields) could be an example of intensification by human land use of the effects of invasive species on native communities (Didham et al. 2007).

Although most research on the consequences of biological invasions has focused on negative effects on native biota and how to mitigate those effects (Gherardi \& Holdich 1999; Rodriguez et al. 2005), there is accumulating evidence that invaders may also benefit native members of their new community (Rodríguez 2006). Invaders often reach high abundances and are incorporated in recipient food webs (Rodríguez 2006). Nevertheless, increases in abundance have been documented in only a few species of native predators (Rodríguez 2006; Barber et al. 2008). We found an unprecedented example of novel prey affecting a large community of predators. 


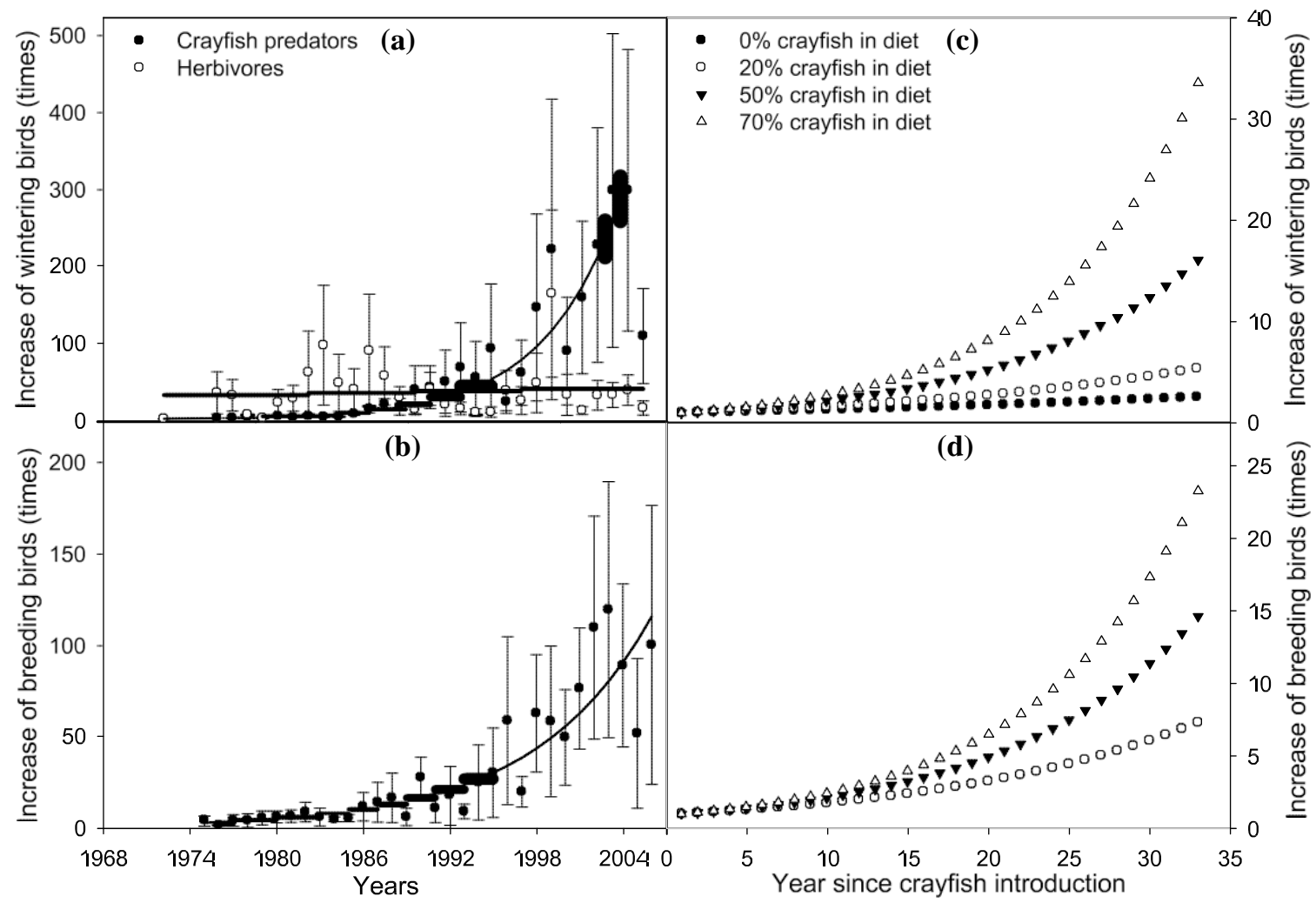

Figure 3. Long-term abundance trends of birds in the Guadalquivir marshes. (a) Abundance of wintering herbivores and crayfish predators since colonization of red swamp crayfish. (b) Changes in the breeding abundances of crayfish predators over the same time period. To make changes in abundance of different species graphically comparable at the same scale, each point represents the average among-species annual increase in abundance with respect to their abundances in $1975\left(\mathrm{~N}_{\mathrm{t}} / \mathrm{N}_{0}\right.$, where $\mathrm{N}_{0}$ is population size in 1975,2 years after crayfish colonization). Error bars are included to show variability among species. Variations in abundance trends of predator birds in the (c) nonbreeding and (d) breeding seasons according to the percentage of crayfish in their diet.

The high reproductive potential of red swamp crayfish (Geiger et al. 2005) is one of the mechanisms through which this species may have increased considerably food availability for predators. The consumption by European predators of medium-sized immature crayfish reduces intraspecific competition and selects for large-sized adult crayfish, which in turn produce even more offspring (Correia 2001). A baseline review showed that increases in crayfish abundance and reproduction could be facilitated by the low number of predator species, especially fishes, in the Guadalquivir marshes relative to the number of predator species in its native range (Liu \& Stiling 2006) (Supporting Information). There are only two predatory species of fish in the Guadalquivir marshes, whereas there are approximately 40 species in the crayfish's native range, and species of fish seem to be more efficient at limiting crayfish densities than terrestrial vertebrates (Mueller \& Frutiger 2001; Neveu 2001; Geiger et al. 2005).
Results of recent studies suggest positive effects of the red swamp crayfish on abundance of a few vertebrate species (Poulin et al. 2007; Rendón et al. 2008). Nevertheless, more than 30 years after introduction of the red swamp crayfish to Europe, this is the first study to demonstrate quantitatively an exponential increase in abundance of crayfish predators following its colonization. A certain threshold density of non-native prey may need to be reached before diets and abundances of predators respond (Rodríguez 2006), which is suggested by our finding that there was a 10-year delay in the incorporation of crayfish into the diet of a generalist predator (Fig. 2). This lag may explain why the growth rate of predator populations was initially low and then increased rapidly after the mid-1980s (Fig. 3). These results emphasize the importance of the information gained by conducting long-term studies of interactions between invaders and native biota (Strayer et al. 2006). 
The fact that herbivore species (e.g., ducks and geese) and species with lower percentages of crayfish in their diets have not increased so much in abundance in the Guadalquivir marshes supports our hypothesis that the abundance of crayfish predators is facilitated by the new prey and not by other changes in their habitat. Other factors, such as the hunting ban in the area after 1983 and the declaration of Doñana National Park in 1989, are of greater benefit to herbivore species, which were hunted intensively, than to crayfish predators (e.g., herons and storks). Differences between local and European abundance trends indicate that larger-scale factors are not driving the increase of predator abundances in the Guadalquivir marshes.

The presence and abundance of top predators is considered highly correlated with total number of species (Sergio et al. 2006), and data on these factors are applied in the design of some protected areas. The Guadalquivir marshes are inhabited by at least 10 predator species that are considered threatened in Europe (Supporting Information) and constitute the primary protected area in Europe for many of these species. Thus, the fact that abundances of these predators are increasing because of the colonization of red swamp crayfish, makes it difficult to manage this invasive species that was known previously for its negative effects on invaded communities (Gherardi \& Holdich 1999; Rodriguez et al. 2005; Gherardi 2007) and was considered one of the least desirable invasive species in Europe (Vilà et al. 2009).

The uncertain trade-off between undesirable and desirable effects of crayfish establishment increases in complexity when one considers there may be additional, unnoticed, undesirable effects associated with the increase in abundance of predators. Crayfish have altered energy flows in Mediterranean wetlands. Much of the detritus in these wetlands is now consumed by red swamp crayfish, which also preys on macrophytes, herbivores, and primary carnivores. The energy gained is directly transferred to top predators, which has resulted in a reduction in the number of trophic levels (Geiger et al. 2005). We found that the abundance of crayfish predators increased exponentially over the last 30 years (Fig. 3) and believe this increase to continue in the absence of other limiting factors, such as nesting-site availability (Jovani \& Tella 2007). We expect that this increase in predator abundance affects species diversity. Top predators are becoming disproportionally abundant with respect to species in lower trophic levels and they consume not only crayfish but native species (Supporting Information). Thus, high levels of predation on native species are expected, especially because annual abundance of red swamp crayfish fluctuates considerably (Courchamp et al. 2000; Roemer et al. 2001; Noonburg \& Byers 2005; Barber et al. 2008). Indeed, there is already evidence of a few such predation events (Z.T. et al., unpublished data) that in the long-term could cause substantial declines in abundances of native insects, amphibians, mammals, and birds, some of which already have unfavorable conservation statuses.

Increases in non-native predator abundance due to increases in abundance of a non-native prey species may lead to an "invasional meltdown" (Simberloff \& Von Holle 1999). That is, one non-native fish species in our study area (e.g., Micropterus salmoides) appears to benefit from the presence of red swamp crayfish. Thus, the negative effects of Micropterus salmoides on native species are likely to be exacerbated by its positive interaction with red swamp crayfish (Geiger et al. 2005).

Behavioral changes in the predator community may occur so that the predators can take better advantage of new prey (Strayer et al. 2006). Marking of individual birds revealed that birds from distant European breeding populations, expected to overwinter in Africa, are increasing in abundance in Guadalquivir in winter (Z.T. et al., unpublished data). These migratory shifts could be partially due to the winter availability of red swamp crayfish in the area. The question then arises whether this invasive species is having large-scale cascading effects (Peters et al. 2007) in other regions and communities.

Our results show that colonization of the study area by red swamp crayfish has altered the abundance of top predators, probably because there have been changes in the energy flow from lower to higher trophic levels (Geiger et al. 2005). This finding suggests that food webs may be much more sensitive to the addition of a single species than theory predicts (Evelelgh et al. 2007).

Only a few eradications have been successful, and typically they were undertaken soon after detection of a new invasive species (Myers et al. 1998, 2000; Mack et al. 2000). After establishment and initial spread, eradication attempts are usually considered unfruitful (but see Edwards \& Leung 2009). The long history of invasion, increase in abundance, and geographic spread of crayfish in Guadalquivir marshlands make the eradication of the species virtually impossible (Geiger et al. 2005). Moreover, unwanted effects could derive from eradication measures (Zavaleta et al. 2001). For example, sudden eradication of invasive prey can lead to high predation on other native species (Moleón et al. 2008) or major declines in abundance of native predators (Lees \& Bell 2008).

Given the extreme difficulties and potential short-term negative consequences of eradication efforts, it may be more effective to control the abundance or the effect of crayfish by, for example, reducing the area of transformed marshes (e.g., rice fields), where proportional consumption of crayfish by predators was much greater than in natural marshes (Fig. 1). Nevertheless, reducing the area of transformed marshland conflicts with agriculture, aquaculture, and crayfish fishing (commercial captures are 4000 t/year in the study area). As in many systems, conservation objectives must be evaluated in the context of the ecosystem, social and economic 
considerations, and the probability that management interventions will be successful.

\section{Acknowledgments}

The authors are grateful to the Natural Processes Monitoring Team of the Doñana Biological Station, especially to M. Máñez for making the long-term data on populations accessible, and to J. Prenda for providing us unpublished data on fish diets. We also thank M. Carrete, E. Revilla, and J. A. Donázar for comments on the paper and $\mathrm{S}$. Young for revising the English. Funds were provided by National Park Project 96B/2002 and by a Consejeria de Medio Ambiente/CSIC agreement.

\section{Supporting Information}

Diet of predator species in the Guadalquivir marshes in the nonbreeding season (Appendix S1) and in the breeding season (Appendix S2), abundances of crayfish predators and herbivores during the bird breeding season in the Guadalquivir area (Appendix S3), local and European trends in abundance of crayfish predators (Appendix S4), and a list of predators on red swamp crayfish in North America (Appendix S5) are available as part of the online article. The authors are responsible for the content and functionality of these materials. Queries (other than absence of the material) should be directed to the corresponding author.

\section{Literature Cited}

Barber, N. A., R. J. Marquis, and W. P. Tori. 2008. Invasive prey impacts the abundance and distribution of native predators. Ecology 89:2678-2683

Beja, P. R. 1996. An analysis of otter Lutra lutra predation on introduced American crayfish Procambarus clarkii in Iberian streams. Journal of Applied Ecology 33:1156-1170.

BirdLife International. 2004. Birds in Europe: population estimates, trends and conservation status. BirdLife International, Cambridge, United Kingdom

Clavero, M., and E. García-Berthou 2005. Invasive species are a leading cause of animal extinctions. Trends in Ecology \& Evolution 20:110.

Correia, A. M. 2001. Seasonal and interspecific evaluation of predation by mammals and birds on the introduced red swamp crayfish Procambarus clarkii (Crustacea, Cambaridae) in a freshwater marsh (Portugal). Journal of Zoology, London 255:533-541.

Courchamp, F., M. Langlais, and S. Sugihara. 2000. Rabbits killing birds: modelling the hyperpredation process. Journal of Animal Ecology 69:154-164.

Crooks, J. A. 2002. Characterizing ecosystem-level consequences of biological invasions: the role of ecosystem engineers. Oikos 97:153-166.

Cruz, M. J., R. Rebelo, and E. G. Crespo. 2006. Effects of an introduced crayfish, Procambarus clarkii, on the distribution of southwestern Iberian amphibians in their breeding habitats. Ecography 29:329-338.

Delibes, M. 1975. Alimentación del milano negro (Milvus migrans) en Doñana, Huelva, España. Ardeola 21:183-207.
Didham, R. K., J. M. Tylianakis, N. J. Gemmell, T. A. Rand, and R. M. Ewers. 2007. Interactive effects of habitat modification and species invasion on native species decline. Trends in Ecology \& Evolution 22:489-496.

Edwards, P. K., and B. Leung. 2009. Re-evaluating eradication of nuisance species: invasion of the tunicate, Ciona intestinalis. Frontiers in Ecology and the Environment 7:326-332.

Evelelgh, E. S., et al. 2007. Fluctuations in density of an outbreak species drive diversity cascades in food webs. Proceedings of the National Academy of Sciences 104:16976-16981.

Finlayson, G., C. Finlayson, and J. M. R. Espejo. 2008. Dynamics of a thermo-Mediterranean coastal environment-the Coto Doñana National Park. Quaternary Science Reviews 27:2145-2152.

Franco, A., and M. Rodriguez. 2001. Libro rojo de los vertebrados amenazados de Andalucía. Consejería de Medio Ambiente, Junta de Andalucía.

Geiger, W. P., P. Alcorlo, A. Baltanas, and C. Montes. 2005. Impact of an introduced crustacean on the trophic webs of Mediterranean wetlands. Biological Invasions 7:49-73.

Gherardi, F. 2006. Crayfish invading Europe: the case study of Procambarus clarkii. Marine and Freshwater Behaviour and Physiology 39:175-191.

Gherardi F. 2007. Understanding the impact of invasive crayfish. Pages 507-542 in F. Gherardi, editor. Biological Invaders in Inland Waters: profiles, distribution, and threats. Springer, Dordrecht, The Netherlands.

Gherardi, F., and P. Acquistapace. 2007. Invasive crayfish in Europe: the impact of Procambarus clarkii on the littoral community of a Mediterranean lake. Freshwater Biology 52:1249-1259.

Gherardi, F., and D. M. Holdich, editors. 1999. Crayfish in Europe as alien species. How to make the best of a bad situation? A. A. Balkema, Rotterdam.

Gurevitch, J., and D. K. Padilla. 2004. Are invasive species a major cause of extinctions? Trends in Ecology \& Evolution 19:470-474.

Jovani, R., and J. L. Tella. 2007. Fractal nest distribution produces scalefree colony sizes. Proceeding of the Royal Society of London B 274:2465-2469.

Lees, A. C., and D. J. Bell. 2008. A conservation paradox for the 21st century: the European wild rabbit Oryctolagus cuniculus, an in vasive alien and an endangered native species. Mammal Review 38:304-320.

Liu, K., and P. Stiling. 2006. Testing the enemy release hypothesis: a review and meta-analysis. Biological Invasions 8:1535-1545.

Lodge, D. M., C. A. Taylor, D. M. Holdich, and J. Skurdal. 2000. Nonindigenous crayfishes threaten North American freshwater biodiversity: lessons from Europe. Fisheries 25:7-20.

Lozano-Montes, H. M., T. J. Pitcher, and N. Haggan. 2008. Shifting environmental and cognitive baselines in the upper Gulf of California. Frontiers in Ecology and Environmental Biology 6:75-80.

Mack, D., et al. 2000. Biotic invasions: causes, epidemiology, global consequences, and control. Ecological Applications 10:689710.

Moleón, M., P. Almaraz, and J. A. Sánchez-Zapata. 2008. An emerging infectious disease triggering large-scale hyperpredation. Public Library of Science ONE 3 DOI: 10.1371/journal.pone.0002307.

Mueller, R., and A. Frutiger. 2001. Effects of intensive trapping and fish predation on an (unwanted) population of Procambarus clarkii. In Abstracts of Annual meeting of the North American Benthological Society North American Benthological Society, LaCrosse, Wisconsin, June 3-8, 2001.

Myers, J. H., A. Savoie, and E. Randen. 1998. Eradication and pest management. Annual Review of Entomology 43:471-491.

Myers, J. H., D. Simberloff, A. M. Kuris, and J. R. Carey. 2000. Eradication revisited: dealing with non-indigenous species. Trends in Ecology \& Evolution 15:316-320.

Neveu, A. 2001. Can resident carnivorous fish slow down introduced alien crayfish spread? Efficacity of 3 fish species versus 2 crayfish 
species in experimental design. Bulletin Français de la Pêche et Pisciculture 361:683-704.

Noonburg, E. G., and J. E. Byers. 2005. More harm than good: when invader vulnerability to predators enhances impact on native species. Ecology 86:2555-2560.

Peters, D. P. C., O. E. Sala, C. D. Allen, A. Covich, and M. Brunson. 2007. Cascading events in linked ecological and socioeconomic systems. Frontiers in Ecology and Environmental Biology 5:221-224.

Poulin, B., G. Lefebvre, and A. J. Crivelli. 2007. The invasive red swamp crayfish as a predictor of Eurasian bittern density in Camargue, France. Journal of Zoology 273:98-105.

Rendón, M. A., A. J. Green, E. Aguilera, and P. Almaraz. 2008. Status, distribution and long-term changes in the waterbird community wintering in Doñana, south-west Spain. Biological Conservation 141:1371-1388.

Rodríguez, L. F. 2006. Can invasive species facilitate native species? Evidence of how, when, and why these impacts occur. Biological Invasions 8:927-939.

Rodriguez, C. F., E. Becares, and M. Fernandez-Alaez. 2003. Shift from clear to turbid phase in Lake Chozas (NW Spain) due to the introduction of American red swamp crayfish (Procambarus clarkii). Hydrobiologia 506:421-426.

Rodriguez, C. F., E. Becares, M. Fernandez-Alaez, and C. FernandezAlaez. 2005. Loss of diversity and degradation of wetlands as a result of introducing exotic crayfish. Biological Invasions 7:75-85.

Roemer, G. W., T. J. Coonan, D. K. Garcelon, J. Bascompte, and L. Laughrin. 2001. Feral pigs facilitate hyperpredation by golden eagles and indirectly cause the decline of the island fox. Animal Conservation 4:307-318.
Sala, O. E., et al. 2000. Global biodiversity scenarios for the year 2100 . Science 287:1770-1776.

Schiffman, P. M. 1994. Promotion of exotic weed establishment by endangered giant kangaroo rats Dipodomys ingens in a California grassland. Biodiversity and Conservation 3:524-537.

Sergio, F., I. Newton, L. Marchesi, and P. Pedrini. 2006. Ecologically justified charisma: preservation of top predators delivers biodiversity conservation. Journal of Applied Ecology 43:1049-1055.

Simberloff, D., and B. Von Holle. 1999. Positive interactions of nonindigenous species: invasional meltdown? Biological Invasions 1:21-32.

Snyder W. E., and E. W. Evans. 2006. Ecological effects of invasive arthropod generalist predators. The Annual Review of Ecology, Evolution, and Systematic 37:95-122.

Strayer, D. L., V. T. Eviner, J. M. Jeschke, and M. L. Pace. 2006. Understanding the long-term effects of species invasions. Trends in Ecology \& Evolution 21:645-651.

Van Riel, P., K. Jordaens, A. M. Frias Martins, and T. Beckeljau. 2000. Eradication of exotic species. Trends in Ecology \& Evolution 15:515.

Vilà, M., et al. 2009. How well do we understand the impacts of alien species on ecosystem services? A pan-European, cross-taxa assessment. Frontiers in Ecology and Environment DOI:10.1890/080083.

Wittenberg, R., and M. J. W. Cock. 2001. Invasive alien species. How to address one of the greatest threats to biodiversity: A toolkit of best prevention and management practices. CAB International, Wallingford, Oxon, United Kingdom.

Zavaleta, E. S., R. J. Hobbs, and H. A. Mooney. 2001. Viewing invasive species removal in a whole-ecosystem context. Trends in Ecology \& Evolution 16:454-459.

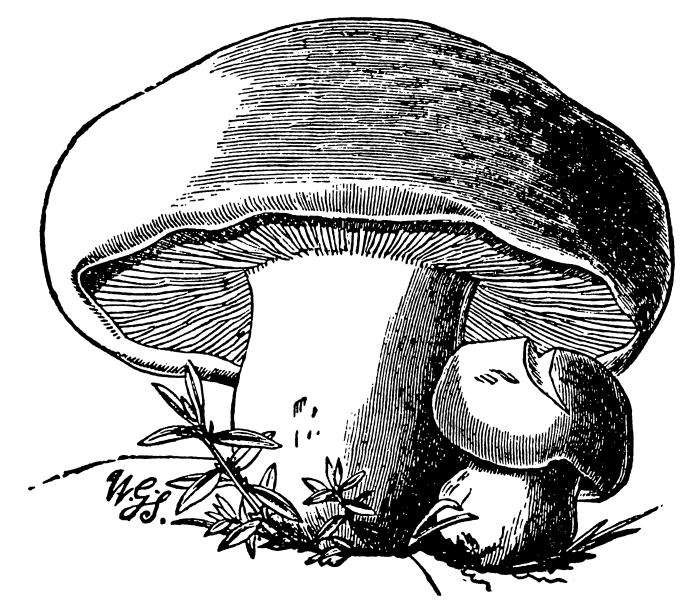

